\title{
Food insecurity and intimate partner violence against women: results from the California Women's Health Survey
}

\author{
Joni L Ricks ${ }^{1, *}{ }^{\dagger}$, Susan D Cochran ${ }^{1}$, Onyebuchi A Arah ${ }^{1}$, John K Williams ${ }^{2}$ and \\ Teresa E Seeman ${ }^{1,3}$ \\ 'Department of Epidemiology, Fielding School of Public Health, University of California, Los Angeles, CA, USA: \\ ${ }^{2}$ Department of Psychiatry \& Biobehavioral Sciences, Semel Institute for Neuroscience and Human Behavior, \\ University of California, Los Angeles, CA, USA: ${ }^{3}$ Division of Geriatrics, David Geffen School of Medicine, University \\ of California, Los Angeles, CA, USA
}

Submitted 17 January 2015: Final revision received 3 April 2015: Accepted 15 May 2015: First published online 22 June 2015

\begin{abstract}
Objective: To investigate the association between food insecurity and intimate partner violence in a population-based sample of heterosexual women.

Design: Logistic regression was used to evaluate the association between three levels of food insecurity and intimate partner violence.

Setting: Data from 6 years of the California Women's Health Survey.

Subjects: Randomly selected women ( $n$ 16 562) aged 18 years and older from the State of California, USA.

Results: We found: (i) that African-American women had a higher prevalence of food insecurity and were more likely to report severe intimate partner violence; (ii) a strong positive association between food insecurity and intimate partner violence; (iii) evidence of effect modification of the association between food insecurity and intimate partner violence by marital status; and (iv) higher odds of intimate partner violence among those reporting more severe food insecurity. Conclusions: Food insecurity is an important risk indicator for intimate partner violence among women. Understanding the factors that put women, especially minority women, at greatest risk facilitates intervention development.
\end{abstract}

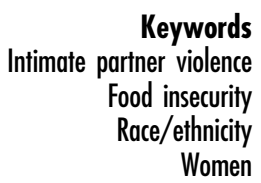

Food security is defined as the access by all people at all times to enough food for an active, healthy life. It involves two aspects of accessibility: (i) availability of food; and (ii) ability to acquire food ${ }^{(1,2)}$. Food insecurity, or lack of access to enough food, has its greatest impact on the most vulnerable of populations, with women as well as African-American and Hispanic households most disproportionately affected ${ }^{(3,4)}$. Women, due to many macro-structural reasons including power inequality, make up a larger number of those in poverty and thus are at greater risk of experiencing food insecurity ${ }^{(5)}$. Moreover, a prior study using the 2004 wave of the California Women's Health Survey demonstrated that even when controlling for the most important predictor of food insecurity, namely income ${ }^{(6)}$, African-American and Hispanic women were at a higher risk of food insecurity than White non-Hispanic women ${ }^{(7)}$.

Besides physical hunger, researchers have demonstrated that there are several physical, psychological and social

† Correspondence address: UCLA Office of Information Technology (OIT), Box 951557, 5308 MS, Los Angeles, CA 90095-1557, USA. consequences of food insecurity that affect quality of life ${ }^{(1,8-10)}$. Research from the USA and Canada establishing the association between food insecurity and psychological and social outcomes has prompted researchers to investigate the role of food insecurity in intimate partner violence (IPV). For example, a study by Tolman and Rosen $^{(11)}$ examined the link between IPV and material hardships such as eviction, homelessness and household food insufficiency (whether the respondent's family had enough food to eat) among 753 women who were current welfare recipients in Michigan. One-quarter of that sample reported having experienced physical violence in the 12 months prior to interview and nearly two-thirds reported physical violence during their lifetimes. Among the women who reported more severe abuse $(51 \%$ of the sample), the investigators compared recent reporters (abuse in 12 months prior to interview) and past reporters, and found that 35.7 and $26.5 \%$, respectively, reported food insufficiency in the past year. Although these findings are from a high-risk population, the observations underscore an especially strong connection between severe physical abuse and food insufficiency. 
Research suggests that food insecurity is linked to violence in any of three main ways ${ }^{(3,12-14)}$. First, economic abuse can produce food insecurity. Economic abuse refers to the denial of adequate access to financial resources, which typically refers to one partner in a relationship controlling and restricting access to finances by the other partner ${ }^{(5)}$.

Second, individuals who escape abusive situations may disproportionately rely on financial assistance and lowwage jobs for survival. Thus, these individuals lack the ability to acquire food because they are unable to afford it due to their tenuous financial status. This can result in increasing their risk of food insecurity. Similar to the view that economic abuse can produce food insecurity, IPV may generate a greater risk for food insecurity that is also moderated by the abused individual's current financial status. Abused individuals with a lower income are often at greater risk of food insecurity after experiencing IPV, compared with those with a higher income. Moreover, there is evidence from several US studies that factors that affect a person's ability to afford basic necessities including food, such as raising young children and marital status, can also be moderators ${ }^{(15,16)}$.

Third, it is possible that an environment that gives rise to food insecurity may also increase the rate of violence ${ }^{(17)}$. A strong example of this is poverty: it is associated with an increased risk for both IPV and food insecurity $(6,18,19)$. Related to this point is the fact that food insecurity can also be conceptualized as an indicator of financial stress and financial stress is known to precipitate $\operatorname{IPV}^{(12,14)}$.

While links between food insecurity and IPV have been made, the few previous studies have primarily investigated this association using restricted populations of women including welfare recipients and specific case studies ${ }^{(3,11,13,20)}$. The current study expands the present understanding of food insecurity and IPV by focusing on how these factors relate among women of colour. Additionally, the study identifies how food insecurity uniquely affects women of colour, especially African-American women.

For the current study, we use the California Women's Health Survey (CWHS) to examine the association between food insecurity and IPV in a larger, more socio-economically and racially heterogeneous population than heretofore has been possible. The analysis aims to focus on the following key questions: (i) Are there racial/ethnic differences in both food insecurity and IPV? (ii) Are there racial/ethnic differences in the association between food insecurity and IPV? (iii) Are there important moderators of the association between food insecurity and IPV? (iv) Is there a detectable association between levels of food insecurity and IPV?

\section{Experimental methods}

\section{Data}

To address our research questions and test our hypotheses about food insecurity and IPV, we analysed data from
16562 women interviewed in the 1999-2001 and 2003-2005 CWHS. The CWHS is an annual household-based telephone survey that uses random digit dialling to obtain its samples. Data are collected annually through a computer-assisted telephone survey of approximately 4000 randomly selected California women. All women aged 18 years and older who live in a selected household are eligible to participate in the survey; if more than one woman in a chosen household is eligible, then one is selected at random as a participant. The CWHS collects data on a variety of social and health outcomes including food insecurity, domestic violence, alcohol and tobacco use, family planning, obesity and sociodemographic variables ${ }^{(21)}$. The survey protocol and questionnaire used to conduct the CWHS are reviewed and approved annually by the State of California's Committee for the Protection of Human Subjects ${ }^{(21)}$. The current study used data on a sub-sample of CWHS respondents who were currently in a relationship, married or unmarried, at the time of interview. As the research did not involve human subjects, it was exempt from institutional review board review by the University of California, Los Angeles Office of the Human Research and Protection Program.

The sub-sample of the CWHS used for analysis includes a representative sample of currently coupled women who self-identified as African-American or Hispanic ${ }^{(21)}$. The choice was made to merge several years (1999-2001, 2003-2005) together to have the ability to conduct a meaningful analysis with enough power to detect differences among racial/ethnic groups. The year 2002 was not included in the sample due to substantial changes in the questions pertaining to IPV for that year.

\section{Main explanatory variable: food insecurity}

The CWHS measures food insecurity using the six-item short form of the US Department of Agriculture's Household Food Security Module. It is a subset of the longer eighteen-item module. It assesses three levels of food insecurity in the last 12 months: (i) food security; (ii) low food security; and (iii) very low food security ${ }^{(4)}$. These levels are considered appropriate to allow for necessary distinctions in food insecurity levels for both the six-item module and the longer eighteen-item full module ${ }^{(22)}$. The short form of the Household Food Security Module is a reliable and valid measure of food insecurity and has been shown to have sensitivity and specificity comparable to the full eighteen-item module ${ }^{(23)}$. Low food security was defined as answering affirmatively two to four module questions. Very low food security was defined as affirmative responses to five or more questions. A respondent is considered to be at least marginally food secure if he/she has one or more affirmative reports to any of the Household Food Security Module questions ${ }^{(24)}$.

Main outcome variable: intimate partner violence IPV is measured using questions drawn from the Conflict Tactics Scale or CTS ${ }^{(25)}$. Five items from the CWHS were 
used to measure minor and severe physical violence. These questions were asked of all women regardless of relationship status.

The questions referring to minor forms of violence were: (i) 'In the last 12 months has a partner pushed, grabbed, shoved or slapped you?'; and (ii) 'In the last 12 months has your partner thrown something at you?' Minor IPV is defined as any positive report to either minor forms of violence question. The questions referring to severe forms of violence were: (i) 'In the last 12 months has your partner kicked, bit or hit you with a fist?'; (ii) 'In the last 12 months has your partner beaten you up or choked you?'; and (iii) 'In the last 12 months has your partner used a knife on you or fired a gun at you?' Severe IPV was defined as any positive report to any of the three severe violence questions. Any IPV was defined as an affirmative response to any of the violence questions, minor or severe.

The IPV questions were highly consistent across different years of the CWHS. However, in the 1999 survey respondents were asked in four separate questions if they had experienced being pushed, slapped, beaten or choked. The questions in this year were reclassified from four items to two items to match those found in the 2000-2005 surveys.

\section{Confounding variables and other covariates}

Several additional self-reported variables were included in the analysis: race/ethnicity (Hispanic or Latino, AfricanAmerican Non-Hispanic, White Non-Hispanic, Asian/ Other); respondent's age (measured in years); family income as indexed by the federal poverty level or FPL (below 200\% of the FPL $v$. above $200 \%$ of the FPL); children (children present in home $v$. children not present in home); marital status (unmarried couple $v$. married); employment (in the workforce $v$. out of the workforce); education (high school or less $v$. more than high school); and year of survey (1999-2001, 2003-2005). The employment category 'in the workforce' included women who reported working full-time, part-time or being self-employed. The employment category 'out of the workforce' included women who reported being out of work, unable to work, students, homemakers or retired. Categories for incomebased FPL, employment and education were chosen to maintain consistency across survey years and comparability with similar research studies ${ }^{(7,26,27)}$.

\section{Analytical strategy}

Analysis for the current project was conducted using the statistical software packages SAS version 9.2 for Windows and STATA SE version 11. All analyses were weighted to adjust for selection probability, non-response and poststratification to the California population ${ }^{(21)}$. We addressed missing data using the Imputations by Chained Equations (ICE) program in STATA. ICE allows the use of logistic and generalized logit models to impute values for binary and categorical variables ${ }^{(28)}$. Univariate analyses were performed on all variables to describe the sample characteristics and determine the distribution of each variable. We examined differences by IPV for selected categorical and continuous variables using Rao-Scott $\chi^{2}$ and $t$-test statistics, respectively.

We then used weighted logistic regression models, with survey sampling weights, to assess the relationship between food insecurity and IPV. The regression analysis included demographic characteristics as potential confounders of this association. We assessed effect modification between levels of food insecurity and selected demographic factors on the multiplicative scale. Odds ratios and 95\% confidence intervals were reported. Additionally, we calculated predicted probabilities of IPV for each level of food insecurity to help describe the effect measure modification. Due to the number of statistical comparisons performed, significance was evaluated at the standard $\alpha=0.05$ and at the more stringent $\alpha=0 \cdot 01$ levels.

\section{Results}

As shown in Table 1, approximately $22 \%$ of women in the study reported food insecurity, with two-thirds of these women reporting low food insecurity and a third reporting very low food insecurity. The sample included predominantly married women, with almost one-third of the sample reporting a family income below $200 \%$ of the FPL; approximately $11 \%$ of the sample reported family incomes

Table 1 Characteristics of respondents in the California Women's Health Survey (1999-2001, 2003-2005)

\begin{tabular}{|c|c|c|}
\hline Characteristic & $\%$ & $n$ \\
\hline Food secure & 78.40 & 13136 \\
\hline Low food security & 14.14 & 2134 \\
\hline Very low food security & 7.46 & 1107 \\
\hline \multicolumn{3}{|l|}{ Age (years) } \\
\hline Mean & $44 \cdot 0$ & \multirow[t]{2}{*}{16476} \\
\hline SE & $14 \cdot 0$ & \\
\hline \multicolumn{3}{|l|}{ Race/ethnicity } \\
\hline Non-Hispanic White & $52 \cdot 3$ & 9822 \\
\hline African-American & 3.5 & 515 \\
\hline Hispanic & $29 \cdot 2$ & 4883 \\
\hline Other & $15 \cdot 0$ & 1256 \\
\hline \multicolumn{3}{|l|}{ Educational attainment } \\
\hline High school or less & 39.0 & 6238 \\
\hline More than high school & $61 \cdot 0$ & 10232 \\
\hline Income below $200 \%$ of the FPL & 29.9 & 4078 \\
\hline \multicolumn{3}{|l|}{ Children present in home } \\
\hline No & $44 \cdot 3$ & 7353 \\
\hline Yes & 55.7 & 9118 \\
\hline \multicolumn{3}{|l|}{ Employment } \\
\hline Out of workforce & $46 \cdot 7$ & 7534 \\
\hline In workforce & $53 \cdot 3$ & 8939 \\
\hline \multicolumn{3}{|l|}{ Marital status } \\
\hline Married & $90 \cdot 5$ & 15050 \\
\hline Unmarried couple & 9.5 & 1426 \\
\hline
\end{tabular}

FPL, federal poverty level.

Weighted estimates are shown. 
Table 2 Characteristics of respondents in the California Women's Health Survey (1999-2001, 2003-2005) by reported intimate partner violence (IPV)

\begin{tabular}{|c|c|c|c|c|}
\hline Characteristic & No reported IPV (\%) & Any reported IPV (\%) & Minor IPV (\%) & Severe IPV (\%) \\
\hline Total \% & $96 \cdot 3$ & 3.7 & $3 \cdot 0$ & 0.8 \\
\hline Food secure & $79 \cdot 8$ & $52 \cdot 0$ & 53.5 & $46 \cdot 9$ \\
\hline Low food security & 13.5 & $22 \cdot 7$ & $23 \cdot 1$ & 21.5 \\
\hline Very low food security & \multicolumn{2}{|c|}{$P<0.0001$} & $23 \cdot 4$ & 31.5 \\
\hline \multicolumn{5}{|l|}{ Age (years) } \\
\hline Mean & 44.54 & 34.70 & $35 \cdot 17$ & 32.91 \\
\hline SE & \multicolumn{2}{|c|}{$P<0.0001$} & $10 \cdot 84$ & $10 \cdot 24$ \\
\hline \multicolumn{5}{|l|}{ Race/ethnicity } \\
\hline Non-Hispanic White & 53.9 & $40 \cdot 8$ & $42 \cdot 6$ & 34.6 \\
\hline African-American & 3.4 & 5.5 & $5 \cdot 1$ & 6.7 \\
\hline Hispanic & $28 \cdot 0$ & 39.7 & 38.6 & 43.4 \\
\hline \multirow[t]{2}{*}{ Other } & \multirow{2}{*}{\multicolumn{2}{|c|}{$P<0.0001$}} & $13 \cdot 6$ & $15 \cdot 2$ \\
\hline & & & & \\
\hline \multicolumn{5}{|l|}{ Educational attainment } \\
\hline High school or less & $37 \cdot 7$ & 49.2 & $46 \cdot 0$ & $60 \cdot 3$ \\
\hline \multirow[t]{2}{*}{ More than high school } & $62 \cdot 3$ & $50 \cdot 8$ & 54.0 & 39.7 \\
\hline & & & & \\
\hline \multicolumn{5}{|c|}{ Income as indexed by the FPL } \\
\hline Below $200 \%$ & $26 \cdot 2$ & 46.4 & 44.1 & $45 \cdot 8$ \\
\hline \multirow[t]{2}{*}{ Above $200 \%$} & $73 \cdot 8$ & $53 \cdot 6$ & 55.9 & $54 \cdot 2$ \\
\hline & & & & \\
\hline \multicolumn{5}{|l|}{ Children present in home } \\
\hline No & 44.9 & $25 \cdot 6$ & $25 \cdot 9$ & 24.8 \\
\hline \multirow[t]{2}{*}{ Yes } & $55 \cdot 1$ & 74.4 & 74.1 & $75 \cdot 2$ \\
\hline & & & & \\
\hline \multicolumn{5}{|l|}{ Employment } \\
\hline Out of workforce & $46 \cdot 5$ & $42 \cdot 4$ & $41 \cdot 8$ & $44 \cdot 7$ \\
\hline \multirow[t]{2}{*}{ In workforce } & 53.5 & $57 \cdot 6$ & $58 \cdot 2$ & $55 \cdot 3$ \\
\hline & & & & \\
\hline \multicolumn{5}{|l|}{ Marital status } \\
\hline Married & 91.3 & $72 \cdot 8$ & $75 \cdot 1$ & 64.9 \\
\hline \multirow[t]{2}{*}{ Unmarried couple } & 8.7 & $27 \cdot 2$ & 24.9 & $35 \cdot 1$ \\
\hline & & & & \\
\hline
\end{tabular}

FPL, federal poverty level.

Weighted estimates are shown. Differences for categorical variables estimated from Rao-Scott $\chi^{2}$ test. Differences for continuous variable estimated from $t$-test statistic.

below $100 \%$ of the FPL. Approximately $30 \%$ of the sample self-identified as Hispanic and more than $50 \%$ of these women were interviewed in Spanish (data not shown). About $3.5 \%$ of women in this sample of coupled women self-identified as African-American, which is fairly consistent with the approximately 5-6\% of California women who are African-American overall ${ }^{(29)}$. The disparate estimate reflects the fact that a greater proportion of African-American women in the CWHS also reported being 'never married', consistent with national estimates ${ }^{(30)}$. A large portion of the current sample is made of coupled women who selfidentified as White or Hispanic. National studies have also found that White and Hispanic women are more likely to report being in a relationship or married compared with African-American women ${ }^{(31,32)}$.

Selected characteristics of the sample by IPV and severity of IPV are shown in Table 2. When compared with those who reported no history of IPV, women who reported experiencing IPV were more likely to be food insecure, younger, self-identify as either African-American or Hispanic, be less educated, have children less than
18 years of age present in the home, have an income below the $200 \%$ of the FPL and be part of an unmarried couple. Among respondents who reported severe IPV, the majority self-identified as Hispanic, had less education and were a part of an unmarried couple.

The results in Table 3 show that African-American women had over 1.5 times the odds of reporting low or very low food security compared with non-Hispanic White women. Moreover, women who self-identified as Hispanic had almost three times the odds of reporting low or very low food security compared with non-Hispanic White women, even after adjustment. Additionally, individuals who reported more than high school education, being in the workforce and having an income above $200 \%$ of the FPL had lower odds of reporting food insecurity.

African-American women did report higher odds of IPV than White or Hispanic women (Table 3). Both AfricanAmerican and Hispanic women had nearly twice the odds of IPV as non-Hispanic White women in the unadjusted analysis. This effect attenuated somewhat after adjusting for employment status, education level, respondent's age, 
Table 3 Logistic regression analysis of the association of race/ethnicity with food insecurity and intimate partner violence (IPV) among respondents in the California Women's Health Survey (1999-2001, 2003-2005)

\begin{tabular}{|c|c|c|c|c|c|c|c|c|}
\hline & \multicolumn{4}{|c|}{ Food insecurity } & \multicolumn{4}{|c|}{ IPV } \\
\hline & \multicolumn{2}{|c|}{ Unadjusted } & \multicolumn{2}{|c|}{ Adjusted $†$} & \multicolumn{2}{|c|}{ Unadjusted } & \multicolumn{2}{|c|}{ Adjusted $†$} \\
\hline & OR & $95 \% \mathrm{Cl}$ & OR & $95 \% \mathrm{Cl}$ & OR & $95 \% \mathrm{Cl}$ & OR & $95 \% \mathrm{Cl}$ \\
\hline \multicolumn{9}{|l|}{ Race/ethnicity } \\
\hline Non-Hispanic White & 1.00 & - & 1.00 & - & 1.00 & - & 1.00 & - \\
\hline African-American & $2 \cdot 30^{*}$ & $1.78,2.97$ & $1 \cdot 60^{*}$ & $1 \cdot 20,2 \cdot 14$ & $2 \cdot 04^{*}$ & $1 \cdot 33,3.14$ & 1.56 & $1.01,2 \cdot 41$ \\
\hline Hispanic & $8 \cdot 80^{\star}$ & $7.94,9.75$ & $2 \cdot 78^{*}$ & $2 \cdot 45,3 \cdot 16$ & $1.89^{*}$ & $1.54,2 \cdot 32$ & 0.92 & $0.70,1 \cdot 21$ \\
\hline Other & $1 \cdot 68^{*}$ & $1.37,2.07$ & $1.40^{*}$ & $1 \cdot 17,1 \cdot 75$ & $1 \cdot 25$ & $0.88,1.76$ & 1.06 & $0.75,1.51$ \\
\hline Age (years) & - & - & $0.98^{*}$ & $0.97,0.98$ & - & - & $0.94^{\star}$ & $0.93,0.95$ \\
\hline \multicolumn{9}{|l|}{ Educational attainment } \\
\hline High school or less & - & - & 1.00 & - & - & - & 1.00 & - \\
\hline More than high school & - & - & $0.50^{*}$ & $0.68,0.57$ & - & - & 0.88 & $0.68,1 \cdot 14$ \\
\hline \multicolumn{9}{|c|}{ Income as indexed by the FPL } \\
\hline Above $200 \%$ & - & - & 1.00 & - & - & - & 1.00 & - \\
\hline Below $200 \%$ & - & - & $5 \cdot 43^{*}$ & $4 \cdot 76,6 \cdot 20$ & - & - & $1 \cdot 60^{*}$ & $1.23,2.08$ \\
\hline \multicolumn{9}{|l|}{ Employment } \\
\hline Out of workforce & - & - & 1.00 & - & - & - & 1.00 & - \\
\hline In workforce & - & - & $0.83^{*}$ & $0.74,0.93$ & - & - & 1.22 & $1.00,1.49$ \\
\hline
\end{tabular}

FPL, federal poverty level.

${ }^{\star} P<0.01$.

†Adjusted models include age, race, education, poverty, employment and survey year.

Table 4 Logistic regression analysis of food insecurity and intimate partner violence (IPV) among respondents in the California Women's Health Survey (1999-2001, 2003-2005)

\begin{tabular}{|c|c|c|c|c|c|c|}
\hline & \multicolumn{6}{|c|}{ IPV } \\
\hline & \multicolumn{2}{|c|}{ Unadjusted $\dagger$} & \multicolumn{2}{|c|}{ Model $1 \ddagger$} & \multicolumn{2}{|c|}{ Model $2 \S$} \\
\hline & OR & $95 \% \mathrm{Cl}$ & OR & $95 \% \mathrm{Cl}$ & OR & $95 \% \mathrm{Cl}$ \\
\hline \multicolumn{7}{|l|}{ Food security } \\
\hline Food secure & 1.00 & - & 1.00 & - & 1.00 & - \\
\hline Low food insecurity & $2 \cdot 56^{\star}$ & $2.03,3.23$ & $2.04^{*}$ & $1.56,2.66$ & $2.01^{*}$ & $1.51,2.67$ \\
\hline Very low food insecurity & $5 \cdot 78^{*}$ & $4.53,7.36$ & $5 \cdot 03^{*}$ & $3.83,6.60$ & $4.93^{\star}$ & $3.68,6.61$ \\
\hline Age (years) & $0.94^{*}$ & $0.93,0.95$ & $0.94^{*}$ & $0.93,0.95$ & $0.95^{\star}$ & $0.94,0.95$ \\
\hline \multicolumn{7}{|l|}{ Race/ethnicity } \\
\hline Non-Hispanic White & 1.00 & - & 1.00 & - & 1.00 & - \\
\hline African-American & $2.04^{*}$ & $1.33,3.14$ & 1.49 & $0.96,2.32$ & 1.48 & $0.95,2.30$ \\
\hline Hispanic & $1.89^{*}$ & $1.54,2.32$ & 0.87 & $0.67,1.14$ & 0.86 & $0.66,1.13$ \\
\hline Other & 1.25 & $0.88,1.76$ & $1 \cdot 11$ & $0.79,1.58$ & $1 \cdot 11$ & $0.78,1.56$ \\
\hline \multicolumn{7}{|l|}{ Educational attainment } \\
\hline High school or less & 1.00 & - & 1.00 & - & 1.00 & - \\
\hline More than high school & $1.56^{*}$ & $1.29,1.89$ & 0.99 & $0.77,1.28$ & 1.01 & $0.78,1.31$ \\
\hline \multicolumn{7}{|c|}{ Income as indexed by the FPL } \\
\hline Above $200 \%$ & 1.00 & - & - & - & 1.00 & - \\
\hline Below $200 \%$ & $2 \cdot 21^{*}$ & $1 \cdot 81,2 \cdot 70$ & - & - & 1.06 & $0.79,1.41$ \\
\hline \multicolumn{7}{|l|}{ Employment } \\
\hline Out of workforce & 1.00 & - & 1.00 & - & 1.00 & _- \\
\hline In workforce & 1.19 & $0.99,1.44$ & 1.28 & $1.05,1.57$ & 1.29 & $1.05,1.58$ \\
\hline
\end{tabular}

FPL, federal poverty level.

${ }^{\star} P<0.01$.

†Unadjusted (simple) logistic regressions conducted separately for each predictor.

$\ddagger$ Model 1 adjusted for age, race, education, employment and survey year.

§Model 2 adjustment same as model 1 plus poverty.

income as indexed by the FPL and survey year. In adjusted analyses, only among African-American women did the association remain substantial $(\mathrm{OR}=1.56$; $95 \%$ CI 1.01 , 2.41) as compared with White women. The effect observed for Hispanic women was diminished to an OR of $0.92(95 \%$ CI $0.70,1.21)$.
Results (Table 4) from the models investigating the association between food insecurity and IPV demonstrate that, in the unadjusted and adjusted (model 1) models, women who reported experiencing food insecurity in the last 12 months did report higher odds of IPV compared with women who reported being food secure in the 
Table 5 Logistic regression analysis of intimate partner violence (IPV) with interactions of food insecurity with marital status and children among respondents in the California Women's Health Survey (1999-2001, 2003-2005)

\begin{tabular}{|c|c|c|c|c|c|c|}
\hline & \multicolumn{6}{|c|}{ IPV } \\
\hline & \multicolumn{2}{|c|}{ Model 1† } & \multicolumn{2}{|c|}{ Model 2† } & \multicolumn{2}{|c|}{ Model 3† } \\
\hline & OR & $95 \% \mathrm{Cl}$ & OR & $95 \% \mathrm{Cl}$ & OR & $95 \% \mathrm{Cl}$ \\
\hline \multicolumn{7}{|l|}{ Food security } \\
\hline Food secure & 1.00 & - & 1.00 & - & 1.00 & - \\
\hline Low food insecurity & $1.95^{\star}$ & $1.47,2.60$ & $2 \cdot 41^{*}$ & $1 \cdot 39,4 \cdot 17$ & $1.99^{*}$ & $1.45,2.74$ \\
\hline Very low food insecurity & $4 \cdot 74^{*}$ & $3.52,6.40$ & $6 \cdot 72^{*}$ & $4.06,11 \cdot 14$ & $5 \cdot 77^{\star}$ & $4.17,7.97$ \\
\hline Age (years) & $0.95^{\star}$ & $0.94,0.96$ & $0.95^{\star}$ & $0.94,0.96$ & $0.95^{\star}$ & $0.94,0.96$ \\
\hline \multicolumn{7}{|l|}{ Race/ethnicity } \\
\hline Non-Hispanic White & 1.00 & - & 1.00 & - & 1.00 & - \\
\hline African-American & 1.41 & $0 \cdot 90,2 \cdot 21$ & 1.46 & $0.94,2.28$ & 1.44 & $0.93,2.24$ \\
\hline Hispanic & 0.85 & $0.64,1.12$ & 0.85 & $0.65,1.12$ & 0.88 & $0 \cdot 67,1 \cdot 15$ \\
\hline Other & $1 \cdot 18$ & $0.84,1.67$ & $1 \cdot 10$ & $0.78,1.55$ & $1 \cdot 19$ & $0.84,1.68$ \\
\hline \multicolumn{7}{|l|}{ Educational attainment } \\
\hline High school or less & 1.00 & - & 1.00 & - & 1.00 & - \\
\hline More than high school & 0.96 & $0.75,1.24$ & 0.97 & $0.75,1.25$ & 0.97 & $0.75,1.25$ \\
\hline \multicolumn{7}{|l|}{ Income as indexed by the FPL } \\
\hline Above $200 \%$ & 1.00 & - & 1.00 & - & 1.00 & - \\
\hline Below $200 \%$ & 0.97 & $0.73,1.29$ & 1.04 & $0.78,1.38$ & 1.00 & $0.75,1.32$ \\
\hline \multicolumn{7}{|l|}{ Employment } \\
\hline Out of workforce & 1.00 & - & 1.00 & - & 1.00 & - \\
\hline In workforce & 1.28 & $1.05,1.57$ & $1 \cdot 30$ & $1.06,1.59$ & 1.27 & $1.04,1.55$ \\
\hline \multicolumn{7}{|l|}{ Children present in home } \\
\hline No & 1.00 & - & 1.00 & - & - & - \\
\hline Yes & 1.35 & $1.06,1.71$ & 1.35 & $1.02,1.80$ & - & - \\
\hline \multicolumn{7}{|l|}{ Marital status } \\
\hline Married & 1.00 & - & - & - & 1.00 & - \\
\hline Unmarried couple & $2 \cdot 02^{*}$ & $1.58,2.60$ & - & - & $2 \cdot 37^{\star}$ & $1.67,3.37$ \\
\hline \multicolumn{7}{|l|}{ Food insecurity $\times$ marital status } \\
\hline Food secure and married & - & - & - & - & 1.00 & - \\
\hline Low food security and unmarried & - & - & - & - & 0.89 & $0.51,1.55$ \\
\hline Very low food security and unmarried & - & - & - & - & $0.48^{*}$ & $0.27,0.86$ \\
\hline \multicolumn{7}{|l|}{ Food insecurity $\times$ children } \\
\hline Food secure and no children & - & - & 1.00 & - & - & - \\
\hline Low food security and children & - & - & 0.78 & $0.43,1.42$ & - & - \\
\hline Very low food security and children & - & - & 0.66 & $0.37,1 \cdot 17$ & - & - \\
\hline
\end{tabular}

FPL, federal poverty level.

${ }^{*} P<0.01$.

†Models adjusted for age, race, education, poverty, employment, children, marital status and survey year.

last 12 months, after adjusting for demographic factors. Moreover, the results indicate that this association remained even after the inclusion of common causes of food insecurity and IPV such as income-based poverty, marital status and presence of children in the home (model 2). Additionally, both age and employment were associated with IPV after adjustment for potential confounders (Table 4).

A large portion of the subsequent analysis was dedicated to understanding the influence of potential effect measure modifiers (e.g. marital status and presence of children in the home) on the association between IPV and food insecurity. Table 5 shows the results from this analysis. The first model includes marital status and presence of children in the home as potential correlates of IPV. The results indicate that being unmarried and reporting children in the home were both associated with a higher likelihood of IPV (model 1). The second and third models examine the potential effect modification of marital status and presence of children on the association between food insecurity and IPV. The presence of children in the home did not appear to be an important modifier of the association between food insecurity and IPV. Instead, marital status appeared to have a modifying effect in this regard for those reporting very low food insecurity.

A graphical presentation of the predicted probabilities of IPV by level of food insecurity is shown in Fig. 1, in which potential effect modifier levels are shown as separate lines. Figure 1 depicts the apparent effect that while unmarried women do have a higher probability of IPV for all levels of food insecurity, the difference between the two groups widens among respondents reporting low food insecurity and then begins to converge among women reporting very low food insecurity. A test of group differences revealed that the probability of IPV was significantly higher among unmarried women who reported being food secure $(P<0 \cdot 0001)$ or having low food insecurity $(P<0.005)$ but not very low food insecurity $(P<0.63)$ as compared with married women. Additionally, the 


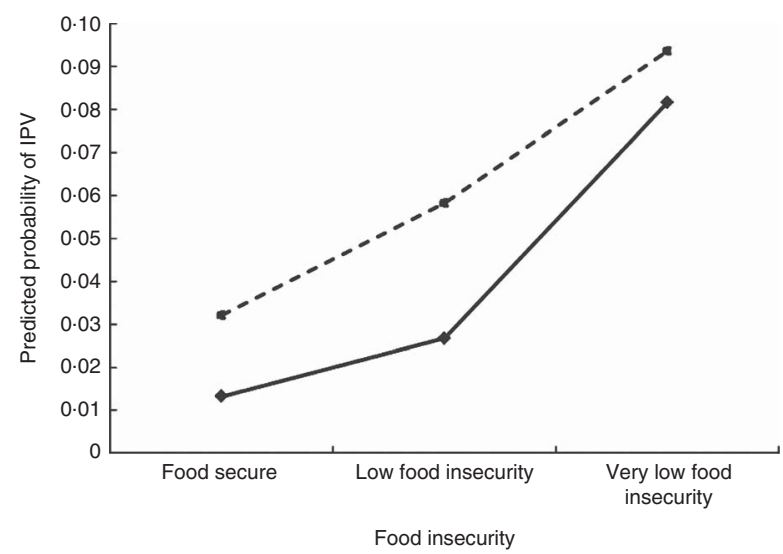

Fig. 1 Intimate partner violence (IPV) and food insecurity: effect modification by marital status $(-\downarrow$, married; - - -- , unmarried couple) among respondents in the California Women's Health Survey (1999-2001, 2003-2005). The estimated probabilities of IPV and $95 \%$ confidence interval taken from the logistic models are plotted $v$. the three levels of food insecurity

probability of IPV for unmarried women appeared almost linear with respect to food insecurity levels.

All models used in the analysis showed a strong relationship between IPV and food insecurity (Table 5). Because food insecurity was measured on three levels (food secure, low food insecurity and very low food insecurity) it was possible to examine if there was a detectable relationship between more severe food insecurity and increasingly higher odds of IPV. The odds of IPV for individuals reporting very low food insecurity was nearly 2.5 times higher than the odds of IPV for participants reporting low food insecurity.

\section{Discussion}

Overall, the present study demonstrates a strong positive association between reporting food insecurity and a higher risk of IPV among coupled women in California. While a link has been demonstrated previously ${ }^{(3,11,13,20)}$, the current analysis, in particular, expands our understanding to a much more generalizable population of coupled women $^{(4)}$. The current analysis produced findings consistent with similar research in the US context that are worth noting ${ }^{(33,34)}$. Both African-American and Hispanic women in the present study reported more severe food insecurity than non-Hispanic White women. Previous research demonstrated similar findings among both economically mixed populations ${ }^{(35)}$ and low-income populations $^{(36)}$ in the USA. Past research and the current analysis have shown that self-reported race/ethnicity is an important correlate of both IPV and food insecurity ${ }^{(37)}$.

There were a number of findings of particular interest in the present study. The first finding was the expected impact that income-based poverty and other common causes of food insecurity and IPV have on the relationship between food insecurity and IPV. Previous studies in the USA found a strong relationship between IPV and socioeconomic measures such as poverty even after adjusting for demographic characteristics ${ }^{(27,38)}$. In the current study, income-based poverty, marital status, educational attainment and presence of children in the home were all strongly associated with both factors in the unadjusted models, and when their effects were added to the full model, the association between food insecurity and IPV remained robust.

A second finding of interest was the relationship between levels of food insecurity and IPV. While food insecurity was closely associated with IPV, the risk of IPV was much higher among those reporting the most severe form of food insecurity. Previous research ${ }^{(36,37)}$ in the USA showed that individuals reporting very low food insecurity were also more likely to report lower income, minority race/ethnicity, lack of employment and receipt of social services such as food stamps, all of which were associated with increased risk of IPV.

A third finding to note is the modifying effect of marital status. Unmarried women had a higher probability of IPV for all levels of food insecurity than had married women. However, the difference between the married and unmarried women widened among respondents reporting low food insecurity and then converged among women reporting very low food insecurity. Understandably, research on IPV is focused on the experiences of individuals in couples, usually cohabitating or being married. Researchers have consistently shown, mostly in crosssectional studies, that cohabitating couples have higher rates of IPV than married couples ${ }^{(39-41)}$, although recent studies in the USA have begun to challenge the accepted notion that cohabitating couples are on average more violent or more prone to violence than their married counterparts $^{(15)}$. It appears that when couples are followed over time, a selection effect emerges. The most violent unmarried cohabitating couples will self-select out of the pool of couples that eventually marry. The selection effect gives the false impression that married couples are less violent. This is not to say that there is no true difference between the two groups, but cross-sectional studies conflate selection and structural properties ${ }^{(15)}$.

The current study found that women who reported being part of an unmarried couple also reported a higher level of IPV, regardless of whether they were food secure or insecure, which is consistent with a possible selection effect. However, we also found that among the most foodinsecure women, the difference in probability of IPV between married and unmarried was greatly diminished. Both married and unmarried women experienced a noticeably elevated probability of IPV in the very low food insecurity group as compared with women reporting food security or low food insecurity. This suggests that the effect of economic distress might be more acute in this group, off-setting the protective effect of marriage. 
Moreover, economic distress has been shown in previous research in the USA to precipitate marital dissatisfaction and family conflict, two factors known to be associated with $\operatorname{IPV}^{(14)}$.

The last finding to note was that several covariates were found to be associated with both food insecurity and IPV, including age, educational attainment and employment status. Similar to findings by other US researchers ${ }^{(7,34,42)}$, higher age was consistently associated with lower odds of food insecurity and IPV in both unadjusted and adjusted models. Also as expected, higher educational attainment and being in the workforce were also correlated with less severe food insecurity. This has been documented in previous research ${ }^{(7,43)}$. However, being in the workforce was found to be associated with an increased odds of IPV, which seems contrary to our common understanding of the link between socio-economic status and IPV ${ }^{(34)}$. The association between employment and IPV is complex. Moreover, there is research from the USA supporting the fact that the prevalence of IPV appears higher among employed women who report an unemployed spouse than among employed women with an employed spouse $^{(40,44)}$. Indeed it is possible that a woman's employment may serve as trigger for violence as it might be interpreted by her male partner as a loss of status or power ${ }^{(45)}$.

Due to the cross-sectional nature of the present study, conclusions about the direction of causality in the relationship between food insecurity and IPV cannot be made. Moreover, it is likely that the association is bidirectional $^{(7,10)}$. However, several key conclusions and areas for exploration can be highlighted. First, it is clear that food insecurity and IPV are linked. Studies that have examined this in the past have looked at particularly vulnerable populations. From the current findings, it is important to underscore that women of different sociodemographic and income backgrounds also face food insecurity and IPV, although perhaps at lower rates. Second, the evidence of higher odds of IPV among those reporting more severe food insecurity does highlight a need to focus on at-risk populations. Future research on food insecurity as a point of intervention is needed. Social service and public health agencies may need to especially target food-insecure women as they are particularly vulnerable to IPV. Services frequented by food-insecure women such as food banks and food stamp programme offices could be used as contact points for women lacking access to information and care for IPV. Additionally, women seeking assistance for experiences of IPV should be evaluated for need for referral to available food assistance programmes.

There are limitations to the present study that merit discussion. Sensitive questions, such as those asking about IPV, will raise concerns about social desirability bias and under-reporting ${ }^{(46)}$. Also, the CTS questions included in the CWHS were not well suited to identify non-physical forms of violence against women, such as verbal or emotional abuse ${ }^{(47)}$. Nevertheless, the CTS has been validated and shown to have good reliability in varying populations ${ }^{(25)}$. It has been used in over seventeen countries and has been shown to be a more sensitive instrument than other commonly used measures of violence including the National Crime Victimization Survey ${ }^{(47)}$. Additionally, the response rate for the CWHS waves varied depending on the year, ranging from $46 \%$ in 1999 down to $25 \%$ in 2001 although this is consistent with many recent random-digit-dialling surveys ${ }^{(48)}$. Also, the main confounder, income-based poverty, was only able to be parameterized as a dichotomous factor due to changes in the CWHS over the 6 years used for the analysis. Thus, residual confounding may remain. Additionally, the proportion of coupled women in the current analysis who self-identified as African-American was smaller than the general California population and may have affected our ability to detect racial/ethnic differences in food insecurity and IPV. Last, because the questions on IPV were asked about experiences in the last 12 months, the current analysis focuses on women who are currently in a relationship. However, this excludes previously partnered women who may have also been exposed to IPV.

The strengths of the study include the broadly representative sample of women and the measurement of food insecurity and IPV. The CWHS is a population-based sample of women from the State of California that gives representative estimates of food insecurity and IPV. The serial cross-sectional design provides a large sample size and increased power in which to conduct the study analysis. Therefore, we were able to explore the association between each race/ethnicity with food insecurity and IPV as well as examine the relationship between food insecurity and IPV. Additionally, food insecurity and IPV were measured using items drawn from standardized scales that allowed for comparability with other literature using these scales.

\section{Conclusion}

Food insecurity is an important risk indicator for IPV among women. Investigating what places women, especially minority women, at greatest risk may facilitate the development of more effective intervention. Interventions focused on reducing the incidence of IPV might profitably seek to reach out to women at risk for IPV in places such as food banks and food stamp offices where food-insecure women would be expected to frequent. These locations can provide a neutral setting for IPV prevention education and assistance. Given the number of negative physical and social consequences to improper nutrition and IPV, reducing the impact on the lives of those most vulnerable will require new and innovative ways to reach impacted women. 


\section{Acknowledgements}

Financial support: This research received no specific grant from any funding agency in the public, commercial or not for-profit sectors. Conflict of interest: None. Authorship: J.L.R. conceived the study hypotheses, conducted the data analysis and wrote the manuscript. S.D.C. made substantial contributions to data analysis and the writing of the manuscript. O.A.A. made contribution to data analysis and the writing of the manuscript. J.K.W. and T.E.S. made contributions to writing of the manuscript. Ethics of buman subject participation: The University of California, Los Angeles Office of the Human Research and Protection Program exempted this research from institutional review board review.

\section{References}

1. Campbell CC (1991) Food insecurity: a nutritional outcome or a predictor variable. J Nutr 121, 408-415.

2. Food and Agriculture Organization of the United Nations (2010) The State of Food Insecurity in the World: Addressing Food Insecurity in Protracted Crises. Rome: FAO.

3. Chilton MM, Rabinowich JR \& Woolf NH (2014) Very low food security in the USA is linked with exposure to violence. Public Health Nutr 17, 73-82.

4. Coleman-Jensen A, Nord M \& Singh A (2013) Housebold Food Security in the United States in 2012. Economic Research Report no. ERR-155. Washington, DC: US Department of Agriculture, Economic Research Service.

5. Broża-Grabowska P (2011) Women's experience of poverty in context of power inequality and financial abuse in intimate relationship. Soc Work Soc 9, issue 2; available at http://www.socwork.net/sws/article/view/279/595

6. Rose D (1999) Economic determinants and dietary consequences of food insecurity in the United States. J Nutr 129, 2S Suppl., 517S-520S.

7. Kaiser L, Baumrind N \& Dumbauld S (2007) Who is food-insecure in California? Findings from the California Women's Health Survey, 2004. Public Health Nutr 10, 574-581.

8. Hamelin A-M \& Habicht J-P (1999) Food insecurity: consequences for the household and broader social implications. J Nutr 129, 2 S Suppl., 525S-528S.

9. Chaparro MP, Langellier B, Birnbach K et al. (2012) Nearly Four Million Californians Are Food Insecure. Los Angeles, CA: UCLA Center for Health Policy Research.

10. Quintanilla L (2011) Reductions in SNAP Increase Health Risks for Food Insecure Women. Los Angeles, CA: UCLA Center for the Study of Women.

11. Tolman RM \& Rosen D (2001) Domestic violence in the lives of women receiving welfare: mental health, substance dependence, and economic well-being. Violence Against Women 7, 141-158.

12. Benson ML \& Fox GL (2004) Concentrated Disadvantaged, Economic Distress and Violence Against Women in Intimate Relationship. Rockville, MD: US Department of Justice.

13. Power EM (2006) Economic abuse and intra-household inequities in food security. Can J Public Health 97, 258-260.

14. Benson ML \& Fox GL (2002) Economic Distress, Community Context and Intimate Violence: An Application and Extension of Social Disorganization Theory, Final Report. Rockville, MD: US Department of Justice.
15. Kenney CT \& Mclanahan SS (2006) Why are cohabiting relationships more violent than marriages? Demography $\mathbf{4 3}$, 127-140.

16. Bair-Merritt MH, Holmes WC, Holmes JH et al. (2008) Does intimate partner violence epidemiology differ between homes with and without children? A population-based study of annual prevalence and associated risk factors. $J$ Fam Violence 23, 325-332.

17. Spencer-Walters DT (2011) Reinstate Project Grow! Targeting Food Insecurity Among Survivors of Intimate Partner Violence. Los Angeles, CA: UCLA Center for the Study of Women.

18. Byrne CA, Resnick HS, Kilpatrick DG et al. (1999) The socioeconomic impact of interpersonal violence on women. J Consult Clin Psychol 67, 362-366.

19. Farmer A \& Tiefenthaler J (2003) Explaining the recent decline in domestic violence. Contemp Econ Policy 21, 158-172.

20. Melchior M, Caspi A, Howard L et al. (2009) Mental health context of food insecurity: a representative cohort of families with young children. Pediatrics 124, 564-572.

21. Wayland S, Induni M \& Davis B (2008) California Women's Health Survey. SAS Dataset Documentation and Technical Report 1993-2007. Sacramento, CA: California Department of Public Health.

22. Ohls J, Radbill L \& Schirm A (2001) Housebold Food Security in the United States, 1995-1997: Technical Issues and Statistical Report. Alexandria, VA: US Department of Agriculture, Food and Nutrition Service.

23. Blumberg SJ, Bialostosky K, Hamilton WL et al. (1999) The effectiveness of a short form of the household food security scale. Am J Public Health 89, 1231-1234.

24. Bickel G, Nord M, Price C et al. (2000) Guide to Measuring Household Food Security. Alexandria, VA: US Department of Agriculture, Food and Nutrition Service.

25. Straus MA, Hamby SL, BoneyMcCoy S et al. (1996) The revised Conflict Tactics Scales (CTS2) - development and preliminary psychometric data. J Fam Issues 17, 283-316.

26. Kimerling R, Alvarez J, Pavao J et al. (2007) Epidemiology and consequences of women's revictimization. Womens Health Issues 17, 101-106.

27. Pavao J, Alvarez J, Baumrind N et al. (2007) Intimate partner violence and housing instability. Am J Prev Med 32, 143-146.

28. Trivellore E, Raghunathan JM, Lepkowski J et al. (2001) A multivariate technique for multiply imputing missing values using a sequence of regression models. Surv Methodol 27, $85-95$.

29. US Census Bureau (2011) State and County Quick Facts: California. http://quickfacts.census.gov (accessed January 2012).

30. Dixon P (2009) Marriage among African Americans: what does the research reveal? J Afr Am Stud 13, 29-46.

31. Aughinbaugh A, Robles O \& Sun H (2013) Marriage and divorce: patterns by gender, race, and educational attainment. Monthly Labor Review, October 2013; available at http://www.bls.gov/opub/mlr/2013/article/marriage-anddivorce-patterns-by-gender-race-and-educational-attainment1.htm

32. Bramlett M \& Mosher W (2002) Cohabitation, Marriage, Divorce, and Remarriage in the United States. Atlanta, GA: Centers for Disease Control and Prevention.

33. Neff JA, Holamon B \& Schluter TD (1995) Spousal violence among Anglos, Blacks, and Mexican Americans: the role of demographic. Variables, psychosocial predictors, and alcohol consumption. J Fam Violence 10, 1-21.

34. Field CA \& Caetano R (2004) Ethnic differences in intimate partner violence in the US general population: the role of alcohol use and socioeconomic status. Trauma Violence Abuse 5, 303-317.

35. Chartier K \& Caetano R (2010) Ethnicity and health disparities in alcohol research. Alcohol Res Health 33, 152-160. 
36. Harrison GG, Sharp M, Manalo-LeClair G et al. (2007) Food Security among California's Low-Income Adults Improves, But Most Severely Affected Do Not Share in Improvement. Los Angeles, CA: UCLA Center for Health Policy Research.

37. Marcus A \& Alderson B (2004-2005) Poverty and family resource centers: where we are today. Working Strategies $\mathbf{8}$, issue 2; available at http://www.familyresourcecenters.net/ wp-content/uploads/2013/04/WS-Winter-2004-2005.pdf

38. Macmillan R \& Kruttschnitt C (2005) Patterns of Violence Against Women: Risk Factors and Consequences. Rockville, MD: US Department of Justice.

39. Hegarty KL \& Bush R (2002) Prevalence and associations of partner abuse in women attending general practice: a cross-sectional survey. Aust $N Z J$ Public Health 26, 437-442.

40. Anderson KL (1997) Gender, status, and domestic violence: an integration of feminist and family violence approaches. J Marriage Fam 59, 655-669.

41. Stets J \& Straus MA (1989) The marriage license as a hitting license: a comparison of assaults in dating, cohabiting and married couples. J Fam Violence 4, 161-180.
42. Rivara FP, Anderson ML, Fishman P et al. (2009) Age, period, and cohort effects on intimate partner violence. Violence Vict 24, 627-638.

43. Coker AL, Smith PH, Bethea L et al. (2000) Physical health consequences of physical and psychological intimate partner violence. Arch Fam Med 9, 451-457.

44. DeMaris A, Benson ML, Fox GL et al. (2003) Distal and proximal factors in domestic violence: a test of an integrated model. J Marriage Fam 65, 652-667.

45. Renzetti CM (2009) Economic Stress and Domestic Violence. Harrisburg, PA: VAWnet.

46. Saunders DG (1991) Procedures for adjusting self-reports of violence for social desirability bias. J Interpers Violence $\mathbf{6}$, 336-344.

47. Straus MA (2007) Conflict tactics scales. In Encyclopedia of Domestic Violence, pp. 190-197 [NA Jackson, editor]. New York: Routledge/Taylor \& Francis Group.

48. Schneider KL, Clark MA, Rakowski W et al. (2012) Evaluating the impact of non-response bias in the Behavioral Risk Factor Surveillance System (BRFSS). J Epidemiol Community Health 66, 290-295. 